$$
\begin{aligned}
& \text { dossiê autor } \\
& \text { convidado }
\end{aligned}
$$




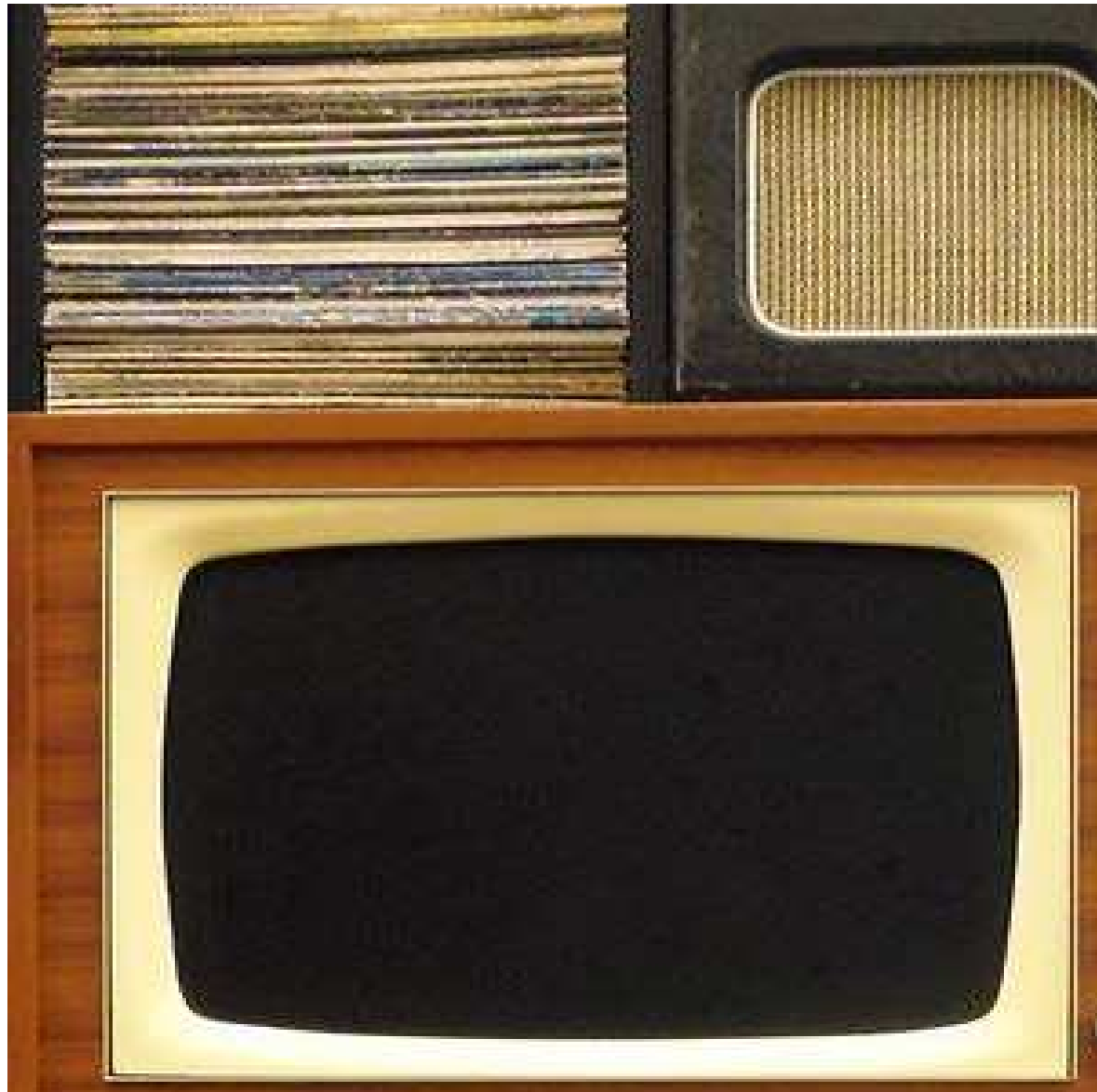

Eirlays
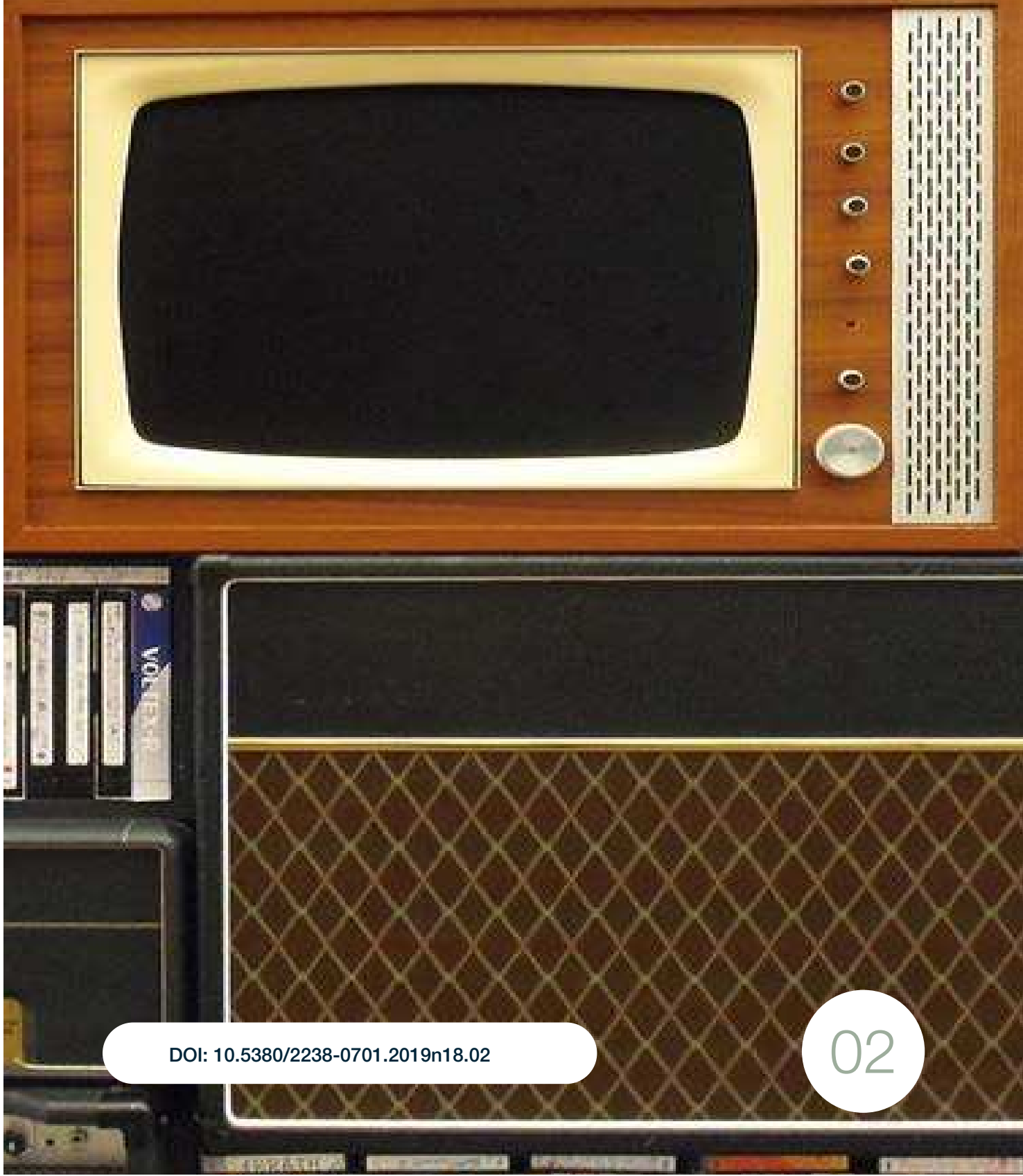
que é filosofia dos meios? 


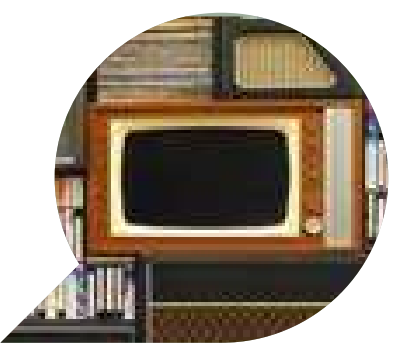

\section{O que é filosofia dos meios? ${ }^{1}$}

LORENZ ENGELL, PROFESSOR DA UNIVERSIDADE BAUHAUS EM WEIMAR ${ }^{1}$

\section{Passar}

Filosofia dos meios é um tema temporário. Ele pode e irá passar. Isso foi escrito pelo filósofo Martin Seel, em sua contribuição para um volume programático intitulado "Filosofia dos meios: explanação de um conceito" de 2003. À época, Seel acreditava que "meios" ou mesmo "mídia" era algo da moda, que tinha a ver com meios de comunicação de massa, os meios técnicos, os meios digitais (sem mencionar as mídias sociais de então) e sua hipertrofia, seu hype. Um tipo supostamente novo de saber e conhecimento, particularmente bem-sucedido nos países de língua alemã, a disciplina acadêmica de Estudos dos Meios deve sua existência a esse modismo. Seel argumentou que, assim que a empolgação sobre o assunto se estabilizasse, ficaria aparente que "a mídia" poderia muito bem ser um novo tema para se filosofar sobre, mas não seria um desafio particular para a filosofia. Enquanto tópico, os meios podem ser melhor considerados com as ferramentas convencionais da Filosofia, sem a necessidade de uma filosofia própria, uma filosofia dos meios.

E é exatamente isso que vemos de forma completamente diferente. A filosofia dos meios não é precisamente um aplicação do conhecimento filosófico a um novo objeto. Os meios desafiam a Filosofia a agir completamente diferente do que era antes. Eles não querem mais ser 
filosofados por nós; querem que pensemos junto a eles. O pensar-sobre será substituído pelo pensar-com. Os meios, portanto, questionam a Filosofia; e por mais paradoxal que seja, eles necessitam da filosofia precisamente para esse propósito e devem tê-la como pressuposto.

Mas mesmo que a avaliação de Seel tenha ocorrido naquele momento com uma intenção polêmica e mesmo que a rejeitemos, ela é, incidentalmente, perfeitamente correta. A própria filosofia dos meios não disse mais nada desde o começo. De fato, como o filósofo dos meios Günter Anders escreveu em seu exílio na Califórnia, em 1956, é uma "filosofia ocasional", uma filosofia do acidental, das circunstâncias. Circunstâncias - tais como condições técnicas, por exemplo, mas também situações políticas ou condições climáticas - têm a ver com o fato de que elas estão constantemente mudando. E esse é exatamente o porquê, justamente por causa dessa natureza provisória, que a filosofia dos meios é tão importante. Ela de fato pode parecer uma nova e badalada subdisciplina da Grande Filosofia. Mas ela assim o parece porque ela representa um desafio muito sério àquela filosofia. Como e quando ela desaparece depende daquilo que ela faz. A filosofia dos meios é, em sua autoimagem, um empreendimento fundamentalmente operativo e operacional. Ela está interessada em intervenções de todos os tipos - e ela própria é uma intervenção. Ela participa - e de modo algum apenas metaforicamente - no corpo material da filosofia pelo qual a própria filosofia, sempre lidando com o conceito, não tem tanto interesse e não precisaria tê-lo. O corpo material da filosofia já inclui a mão da escrita, talvez o meio primário de intervenção filosófica, mais até mesmo do que o cérebro e sua ferramenta, o instrumento de escrita que o guia. Mas também há outros, tais como os corpos de pensamento artificiais, técnicos, materiais, e eles também têm uma participação nas intervenções que são realizadas com ajuda deles. Como o filósofo dos meios Vilém Flusser coloca, a filosofia é dedicada aos gestos que ela faz no mundo e às operações que realiza com a ajuda das coisas.

Na perspectiva da filosofia dos meios, a mera e pura reflexão, sem corpo, não existe; é portanto sempre gesto e ação instrumental. Isso significa que a filosofia dos meios não está apenas comprometida com a estética de tais gestos. Acima de tudo, ela está exposta ao seu caráter temporário e transitório em um mundo de circunstâncias constantemente em mutação, irresistivelmente transformado por tais gestos e operações. 
É portanto uma explícita e afirmativa filosofia da passagem, e não apenas uma afirmação temporária, como Seel argumenta. Portanto, a questão sobre o que realmente é a filosofia dos meios não pode ser respondida pelos meios filosóficos. A questão seria preferencialmente substituída por uma questão acidental, como fez Günter Anders. Onde a filosofia dos meios ocorre, sob quais condições, quando ela se mostra, o que ela empreende, como funciona: essas seriam questões da filosofia dos meios. Em todo o caso, ela está funcionando, para incluir uma frase de Siegfried Kracauer, antes das últimas coisas, onde há pouca mudança; mas não com horizontes finais e abrangentes, verdades eternas e últimos errantes, como faria uma filosofia que não quer passar.

Nesse sentido, a filosofia dos meios é minoritária, está presa ao tempo e ao corpo, aparatos, arranjos e até substâncias, e o que ela explora são precisamente essas amarras. Uma de suas preocupações é emergir, fazer efeito e desaparecer, explorar as condições e modos de progressão dessas amarras e relações, mesmo que sejam dela própria. Isso não faz da filosofia dos meios irrelevante nem dispensável, mas capaz de ação. Essa agência é também absolutamente necessária naquelas áreas onde o corpo institucional da filosofia, a universidade, a academia, e o discurso público e dos meios de comunicação estão interessados. A filosofia dos meios, em defesa das circunstâncias, também é sempre uma política do conhecimento.

\section{Definir}

Existem, é claro, maneiras muito diferentes de abordar a filosofia dos meios. Nem todas elas partem da filosofia acadêmica em si. Uma prática medial-filosófica deve ser relativamente indiscutível, reconhecer a si própria como um trabalho conceitual competente e, de maneira mais aproximada, como uma teoria da ciência. Sua tarefa seria a de esclarecer os conceitos dos estudos dos meios enquanto trabalho meta-teórico e instância de reflexão. Naturalmente, é sobretudo sobre o conceito de meio, em suas numerosas variantes, facetas e múltiplas utilizações e aplicações. Embora tenhamos rejeitado essa abordagem no primeiro parágrafo acima, essa questão talvez se torne interessante onde ela não é limitada a descrever, analisar a esclarecer o uso dos termos em estudos dos meios. Isso 
acontece, por exemplo, quando a filosofia dos meios, tendo em vista a surpreendente heterogeneidade de todos os fenômenos e objetos descritos como "meio" em seu uso conceitual, pergunta a si mesma o que todos eles podem ter em comum quanto à função ou qualidade. Para além do alcance mais restrito do "meio", esse tipo de filosofia dos meiosopera conceitos de "medialidade" ou mesmo de "medial" que fazem um fenômeno ou coisa ser um meio. Aqui, pode ter início uma mudança da crítica estrita do termo para uma ontologia do "medial".

Em uma segunda variante, no entanto, a filosofia dos meios pode proceder também a partir de uma perspectiva histórica, isto é, em termo de história conceitual, metafórica e ideológica. Para esse fim, será necessário questionar conceitos que não se enquadram na formulação relativamente nova de "meio". Outros conceitos podem ter assumido funções na tradição filosófica que são cada vez mais exercitadas pelo conceito atual de meios, ou fenômenos que são entretanto subsumidos sob o conceito de meios. Onde, e como, pergunta tal filosofia dos meios, os meios foram conceitualmente considerados e incorporados em discursos filosóficos, mesmo se um conceito explícito de meios ainda não foi utilizado? Em outras palavras: como o meio se tornou concebível em filosofias completamente distintas?

Essas são atualmente perguntas muito centrais e importantes. Elas vêm de uma natureza filosófica clássica e portanto denotam a área na qual a filosofia e a filosofia dos meios se encontram e se sobrepõem sem quaisquer problemas. Mas tais questões também são temporárias, porque elas são apenas importantes e centrais enquanto há um interesse específico no conceito de meios e um saber sobre os meios cujos termos precisam ser esclarecidos. Assim, diferentemente das questões filosóficas tradicionais, elas já dependem da meia-vida das modas científicas e podem rapidamente se tornar questões da história da ciência. No entanto, a diferença entre os discursos conceitual e histórico seria precisamente esta: a história da ciência está interessada no corpo material e nos processos gestuais e materiais da geração e uso do conhecimento, enquanto a história dos conceitos opera de forma abstrata. 


\section{Operar}

É justamente por essa razão e nesse ponto que ao menos duas outras variantes filosóficas se tornam visíveis. Ambas dão um passo decisivo. Elas distanciam-se dos termos teóricos da Teoria dos Meios e, em seu lugar, investigam suas condições de origem e circulação. A suposição básica da filosofia dos meios desse terceiro tipo é de que as noções, incluindo os conceitos filosóficos, são condicionadas pelo extraconceitual do qual elas emergem e no qual elas, por sua vez, reentram. Elas estão comprometidas com as condições materiais de sua criação e eficácia e não podem simplesmente emergir e se desenvolverem a partir de si mesmas. Friedrich Nietzsche já escreveu: "Nossos instrumentos de escrita colaboram com nossos pensamentos". E um século antes, na obra de Georg Christoph Lichtenberg, nós encontramos o notável pensamento: "Eu sempre tive noções mais amplas de 'sala' do que a das pessoas comuns. Muitas das nossas ideias dependem da localização delas e você pode olhar para elas como uma espécie de segundo corpo". E, finalmente, Friedrich Engels escreveu: "Tudo o que põe as pessoas em movimento precisa passar por suas mentes, mas a forma que assume nas mentes depende muito das circunstâncias". Então mais uma vez retornamos à filosofia dos meios como uma filosofia do ocasional, uma filosofia das circunstâncias e, portanto, de assuntos temporários. E mesmo os pensamentos mais profundos revelam-se transitórios em um sentido muito específico, quase técnico, porque, para poderem funcionar, poderem ser pensados e continuados, poderem ser reconhecidos, eles têm que circular. Têm de se mover, têm de passar por nós. Isso também é sabido já há um bom tempo; o livro de Josias Ludwig Gosch, Ideenumlauf (Circulação de Ideias), de 1789, lida com isso à sua maneira e pode ser lido enquanto um precursor da famosa fórmula de Harold A. Innis de "caminhos de troca da mente", na qual ele se refere à imprensa de massas e seu sistema de distribuição. Ao invés de circular em espaços vazios, os pensamentos circulam com a ajuda e sob o condicionamento de meios de transporte específicos, que naturalmente se inserem naquilo que eles permitem circular.

Tudo isso significa nada mais do que dizer que conceitos filosóficos e não filosóficos - se tornam maleáveis quando eles circulam através de meios; e não apenas isso: inversamente, os meios se tornam concebíveis através do trabalho conceitual. A escrita em si e as técnicas de escrita, 
meios óticos de percepção expandida e observação, ou aparatos de ilusão, tecnologias de cálculo, gravação, transmissão e disseminação: tudo isso, até os dispositivos de ensino, experiência estética ou até mesmo cultura popular tornam algo específico experienciável, imaginável e concebível, que então pode ser levado à filosofia. A própria filosofia, com sua noções de verdade ou humanidade, por exemplo, incluindo aquelas noções que foram concebidas como imutáveis e incondicionais, é também sujeita às condições da impressão de livros, o cenário em perspectiva no teatro, a lanterna mágica, cinematografia, controle remoto, ferramentas de computação, endereçamentos onipresentes e instantâneos. No entanto, expor tudo isso certamente não é mais suficiente para a competência filosófica convencional. Requer um conhecimento preciso acerca do funcionamento e das práticas de aplicação das tecnologias, processos e estéticas em questão.

Conceitos filosóficos emergem de maneira a serem feitos, formados e circulados por meio de ou sob a influência de ferramentas e arranjos materiais nomeáveis. A conceitualização (e, portanto, no sentido mais amplo: a argumentação) é portanto operativa, e seus instrumentos e circunstâncias não permanecem inalterados pelos termos e argumentos, pois eles não apenas os fazem perceptíveis e comunicáveis, mas também, em certa medida, concebíveis e discutíveis.

Tais termos e argumentos condicionais, nos quais as circunstâncias e instrumentos através dos quais o trabalho é realizado e apresentado, agora incluem, de acordo com uma outra variante da filosofia dos meios, o próprio conceito de "meios", em particular. Seja guiado implicitamente ou explicitamente, seja usado filosoficamente, teoricamente ou jornalisticamente, o conceito de meios, ou a suposição de um "medial" e uma "medialidade", precisa ser também compreendido enquanto algo inferido de forma condicional e externa, isto é, como sendo realizado e circulado em cooperação com os meios. Isso deve incluir também os meios que são usados em cada caso. Portanto, mesmo o conceito de meio seria diferente, se a medialidade do livro impresso não fosse a mesma da medialidade da escrita, do telescópio, da imagem em movimento. Qualquer subsunção de um "meio" sob o acesso de uma alegada "medialidade" teria de ser rejeitado: nem todos os meios podem ser abordados ou mesmo entendidos enquanto escrita, enquanto uma instalação de perspectiva ótica ou enquanto poder de computação. 


\section{Refletir}

E essa circunstância, por sua vez, novamente direciona a atenção para a diferença entre a filosofia dos meios e a Filosofia geral, para além da inegável origem da filosofia dos meios na filosofia e sua dependência desta. Uma vez que a filosofia é amplamente um empreendimento monomedial, ou melhor: um empreendimento homomedial. Ela é, ainda mais, um trabalho conceitual, um processo que se dá na linguagem e, na verdade, também na escrita. Ela parte das Escrituras e adentra as Escrituras de novo e de novo. A escrita e a leitura são as suas formas primárias de produção e circulação. É claro, nem mesmo a filosofia dos meios altera isso - ou talvez apenas um pouco. Ela também, como aqui, desdobra-se na linguagem, em forma impressa e, portanto, sujeita às condições limítrofes da escrita, impressão, leitura e audição dos meios. Ela não pode conceber o que não é possível em tais meios.

No entanto, a filosofia dos meios, mesmo se continuar a escrever, muda para a heteromedialidade. Assume que processos também estão acontecendo em meios que não a linguagem, escrita ou impressa, que podem corresponder às operações da filosofia no campo linguístico enquanto seus equivalentes funcionais. Assume que a participação dos meios em seus próprios conceitos, como mostrado acima, não é apenas refletida na linguagem na qual eles próprios operam. Mais do que isso, os meios podem sempre desenvolver uma autoconcepção que, em vez de fornecê-los apenas à filosofia e à argumentação conceitual e tornálos conhecidos, eles também a utilizam operacionalmente em relação a outros meios e não apenas em relação a eles próprios. Não é apenas a filosofia e outras disciplinas e discursos que estão envolvidos naquilo que um meio é e em como ele é compreendido operacionalmente, mas os próprios meios se ocupam disso. Nesse sentido, não somente a ciência, nem somente a filosofia esclarecem, mas também os meios, tacitamente envoltos em suas operações, esclarecem o que eles são e que contribuição eles fazem para aquilo que eles não são. Esse conhecimento implícito dos meios não é de forma alguma restrito a um mero reflexo, como uma relação de meios com eles próprios: diz respeito, é claro, a tudo mais além do respectivo meio, relaciona-se com o mundo e com tudo o que ele abrange.

$E$ esse conhecimento que os meios suportam e instanciam é, 
obviamente, aberto à tradução em termos de outros meios, tal como a filosofia conceitual. Portanto, vale a pena integrá-los no debate filosófico em uma maneira argumentativa. O trabalho da filosofia dos meios é, claramente, levar adiante tal serviço de tradução como uma transformação, uma transição de meios. Não diz respeito à sutil reprodução dos gestos reflexivos dos meios, mas sim à reconstrução desses meios em outro meio filosófico. Sem alteração, isso jamais irá funcionar, mas é precisamente isso que torna a filosofia dos meios produtiva - e um caso temporário, de mudança intensiva. Com ela, a filosofia novamente aprende algo acerca de sua condicionalidade e materialidade - e assim sobre a coisa temporária que lhe é própria. A filosofia percebe mais uma vez que ela não é, de maneira alguma, senhora incondicional em sua própria casa, ou mesmo de qualquer casa. Isso também pode fazer a filosofia ser reconhecível novamente.

\section{Conhecer}

As mudanças que a filosofia dos meios descreve não afetam apenas os meios. E não dizem respeito apenas ao conhecimento. Elas dizem respeito ao sentir e experienciar tanto quanto todas as outras formas de relacionamentos e movimentos. No meio filme, por exemplo, pode-se reconhecer uma reflexão sobre o tempo que é equivalente - não igual - a todas as filosofias do tempo, mas que ao mesmo tempo cria o tempo, que funciona pelo tempo enquanto sua matéria prima e enquanto seu produto, fazendo o tempo dar um loop em si mesmo, e que não apenas reflete sobre o tempo. No meio controle remoto nós lidamos com a operação de selecionar, que desenvolve uma complexa lógica modal entre o contingente e o virtual, através da qual o imenso fluxo de imagens se orienta via aparelho e a pessoa que o opera. No diorama, as questões da vida e da morte são negociadas de uma maneira quase dramática, não conceitualmente, mas através das operações de matar e de ressurreição ilusória para a vida eterna. No tuitar ${ }^{2}$ e em outros sistemas de mensagens curtas, o que importa não é o texto e a semântica, mas sim a mera operação de recursão das funções fática e dêitica da comunicação,

2 NdT: Twittering no original, isto é, publicar na rede social Twitter. 
através da qual si-mesmos são gerados. Nós não tuitamos, nós somos tuitados. Essas filosofias mediáticas de tempo, modalidade, vivência e abordagem fática e dêitica, dessa forma, ocorrem em seus respectivos meios, guiadas por seus significados. Novamente, elas não são escritas por filósofos. Filósofos dos meios meramente as expõem e as traduzem da melhor forma possível em filosofia.

Mas como pouca filosofia dos meios se origina dos pensamentos dos filósofos, então pouco dela retorna exclusivamente a eles. Em um ensaio programático, Christiane Voß nos lembra que problemas filosóficos não existem apenas em filosofia e não apenas para filósofos. De forma implícita, Voß estipula uma quinta variante da Filosofia dos meios. Vamos antes tomar as grandes questões centrais da filosofia: o que eu sou capaz de saber? O que eu devo fazer? O que devo esperar? E finalmente, claro: o que é o Humano? Essas questões não são apenas relevantes nas filosofias, abstratas ou sem contexto, mas elas também são relevantes ao mundo em si, incluindo o ser humano. E nós podemos acrescentar a essas grandes questões uma longa cadeia de questões menores, mas não menos importantes: como o amor pode prosperar? A Justiça é possível? O que as coisas querem? Quando a Arte é bela? Onde está a natureza? Todas essas questões não podem ser respondidas de forma alguma sem levarmos os meios em consideração, de acordo com a convicção da filosofia dos meios. Talvez elas nunca tenham sido aptas a serem respondidas sem considerar os meios, mas talvez seja apenas por causa da penetração dos meios técnicos na vida e no mundo em nosso tempo.

O mais fácil de entender é provavelmente a questão do conhecimento. Quase tudo que nós sabemos foi transmitido a nós, nós o sabemos através de meios e a partir de meios. Mas os meios não são neutros, eles marcam o que eles transmitem, têm um efeito sobre, eles apenas processam certas figuras, outras não. Esse envolvimento dos meios naquilo que nós sabemos, incluindo o que sabemos acerca dos meios, não é mais discutido hoje em dia. Fora da mediação, praticamente não existe conhecimento. O conhecimento em si é apenas mais um assunto para a ocasião. Por essa razão, a questão filosófica acerca do conhecimento precisa também ser suplementada pelas considerações sobre meios, ou seja, pela filosofia dos meios. E algo similar agora pode ser dito sobre sentimentos e experiências, esperanças e medos, 
e relações de qualquer tipo, mesmo além das humanas, que não são menos imediatas ${ }^{3}$ do que o conhecimento.

\section{Gerar}

Todas essas questões são ativas nos meios, mas elas não precisam se tornar temáticas e semânticas a princípio. Elas não precisam ser explicitamente, visivelmente e audivelmente discutidas nos meios, como nós vimos. Filmes, por exemplo, não precisam lidar com elas de forma alguma. O controle remoto não lida com contingência e virtualidade, mas move-se nelas, coloca-as em ação e marca tudo aquilo que trocamos com sua ajuda, e aquilo que nos deixa trocar, pela relação recíproca daquilo que é, mas que poderia muito bem não ser, para aquilo que não é, mas que poderia muito bem ser. Portanto, é um grande equívoco da filosofia dos meios restringi-la a como problemas individuais ou tópicos de modos de existência são tratados por meios não escritos. Esse não é o ponto. Não diz respeito à representação do tempo, amor, dinheiro, trabalho ou natureza em determinados meios. Aquilo com o que lidam os filmes, instalações de museus, tuítes ou séries de TV, por exemplo, não é o que importa.

A filosofia dos meios não pensa sobre os meios, mas pensa com eles ou dentro deles. Lida com a capacidade do meio filme de se tornar operacional e expõe a relação dele com o tempo, a luz, a percepção, os objetos técnicos como aspectos básicos do seu método, o qual também gera e determina suas respostas temáticas às questões do amor, justiça ou coisas, ou, para ir além, o que realmente produz tais respostas. Em resumo: o meio é a mensagem, incluindo a mensagem filosófica.

Isso também se aplica a um campo específico da filosofia dos meios, que lida com aquilo que é talvez o mais importante de todas essas grandes questões filosóficas modernas, ou seja, a questão do Humano. O que é o Humano, então, dificilmente pode ser respondido através dos caminhos conceituais da antropologia filosófica por si só, nem mesmo pelos caminhos da pesquisa genética e outros métodos paleoantropológicos. Nada tem questionado tanto a humanidade

3 NdT: Immediate, não em sentido temporal, mas para transmitir a noção de ausência de um meio. 
quanto a desumanidade moderna, a destruição do habitat humano e o desenvolvimento de artefatos técnicos que fornecem funções que tradicionalmente são esperadas apenas de seres humanos. Nessas três áreas, no entanto, deparamo-nos com um massivo envolvimento dos meios. Sem os meios de administração, discussão, separação, segregação e transporte, as desumanidades modernas não seriam possíveis, desde a comunicação via rádio até os grandes muros nas fronteiras. Sem os instrumentos de intervenção técnica na natureza e o controle sobre ela, as relações do homem com o seu habitat seriam diferentes. As capacidades inteligentes dos sistemas técnicos nos confrontam enquanto meios neste exato momento. E aquilo que se aplica à desumanidade e questionamento do homem é mais verdadeiro ainda para a sua criação. O ser humano não existe pura e simplesmente, mas foi gerado, não apenas pela natureza, não apenas por si só, mas também por sua relação com os meios. Tudo isso é motivo suficiente para dar prioridade à questão de uma antropologia dos meios dentro da pesquisa de filosofia dos meios. 


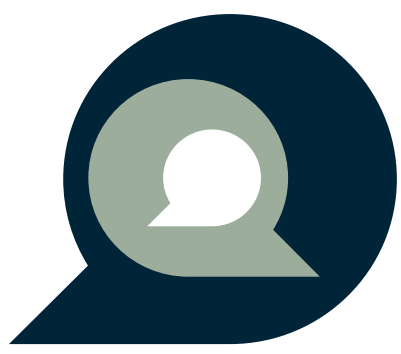

